
\title{
$\angle S$ Research Suare \\ Modifying the Mini Cog to Screen for Cognitive Impairment in Non-literate Individuals
}

\section{Shambhu Prasad Adhikari ( $\nabla$ spsaur@gmail.com )}

Kathmandu University https://orcid.org/0000-0002-2635-6844

\section{Rubee Dev}

University of Alberta

\section{Soo Borson}

University of Washington Seattle Campus: University of Washington

\section{Research}

Keywords: Acceptability and feasibility, dementia and cognitive impairment, literacy, Modified Mini-Cog

Posted Date: March 2nd, 2021

DOl: https://doi.org/10.21203/rs.3.rs-248870/v1

License: (a) (i) This work is licensed under a Creative Commons Attribution 4.0 International License. Read Full License 


\section{Abstract}

Objectives: The Mini-Cog, a rapid, valid, and reliable screening tool for cognitive impairment, consists of 3-word recall and an executive Clock-Drawing Test (CDT). However, CDT requires at least basic literacy and cultural exposure to analog clocks, conditions not met in many population groups around the world. We developed a modification of the Mini-Cog (MMC) for use with non-literate and literate individuals.

Methods: Participants were adults ( $\geq 60$ years) with no neurological diagnosis, with known cognitive impairment due to stroke, Parkinsonism, traumatic brain injury or Alzheimer's disease, and whose family members were able to read and write. We replaced the CDT with two tasks of everyday life: a serial subtraction task or a multistep performance task. Family members rated the acceptability and feasibility of the Mini-Cog versions using a 6point scale, and completed a proxy-rated cognitive staging tool, the Dementia Severity Rating Scale (DSRS). Spearman's rho, Mann- Whitney $\mathrm{U}$ and Chi-square tests were used to evaluate group differences and associations between measures.

Results: Data were collected from 63 participants ( $75 \% \geq 60$ years, $67 \%$ non-literate). Literacy was associated with CDT (Chi-square strength $0.9, p<0.001$ ). Both MMC versions correlated with DSRS in healthy adults and patients (rho $0.6-0.7, p<0.05$ ). In literate individuals, the acceptability and feasibility of CDT and both alternate distractors were similarly high $(5 / 6)$.

Conclusions: Two alternate distractor tasks may successfully replace CDT in the Mini-Cog. The MMC versions are promising and deserve further study as screening tools for cognitive impairment in larger and more fully characterized samples.

\section{Background}

The Mini-Cog (MC) is a short screening tool for clinically important cognitive impairment, originally developed by Borson et al., in 2000 by combining a short memory test and an executive clock-drawing test (CDT) (1). The choice of 3-item recall as the memory test was based on research showing that this element in the Mini Mental State Examination (MMSE) is the first to be impaired in early Alzheimer's disease $(1,2)$. The CDT serves as an informative distractor: it creates a short recall delay and itself functions as a cognitive test, since it relies on multiple integrated cognitive functions commonly impaired in neurocognitive disorders. The MC is feasible, reliable, valid and time saving for settings in which rapid detection of cognitive impairment is desirable, since it takes just 3 minutes to administer $(1,3)$. It has acceptable sensitivity and specificity for dementia in both clinical and population samples, detects mild cognitive impairment (with less sensitivity and specificity), and has been widely implemented in western clinical settings $(1,2,4)$. McCarten and colleagues highlighted its speed and high acceptance by older veterans (5). Studies have also reported superior screening properties of the MC compared to that of MMSE $(1,6)$ and its psychometric properties have been well established $(1,7)$. Both components of the $\mathrm{MC}$ contribute to detection of dementia (2).

The Mini-Cog is available in many languages (mini-cog.com) and has been used successfully in the United States with both English and non-English speakers with varying levels of education, but its clock drawing component is vulnerable to very low education - uncommon in US-born populations and poorly represented in most research on cognitive impairment. The CDT may not be valid with non-literate individuals, as it generally requires at least a basic education (typically 4-5 years of primary schooling); while oral 3-word recall should not 
be influenced by literacy, clock drawing errors are common and often different in character among individuals with fewer than 5 years of education, obscuring its discriminative power for acquired cognitive impairment (8). To make a MC-like tool feasible for rapid screening of non-literate individuals for cognitive impairment, the CDT must be replaced by another task that serves a similar function. Other screening tests such as the MMSE have been modified for different levels of education (9) but not for non-literate individuals. In the Bangala version of the MMSE, validated in both literate and non-literate groups, Kabir et al. replaced its calculation item with a reallife mathematical calculation task used every day by both literate and non-literate individuals (10). This type of real life task could also potentially replace the $\mathrm{CDT}$, but because a small percentage of non-literate individuals may not be able to do it, we introduced a multistep matching performance task as another option, reasoning from the multistep command used in the MMSE (9). We created two modified versions of the Mini Cog (MMC), one using an everyday serial subtraction task (SST) and the other a multistep performance task (MPT) in place of CDT (Appendix 1).

\section{Methods}

\section{Setting and Participants}

Nepali-speaking individuals were recruited among patients and family members seen in a community hospital in Nepal. Purposive sampling was used to identify potential participants for screening test comparisons. Inclusion criteria generated two groups: older adults ( $\geq 60$ years) with no diagnosis of neurological disease and individuals of any age with diagnosis of a neurological disease (stroke, Parkinson's disease, traumatic brain injury or Alzheimer's disease) based on medical records. All had to be able to understand Nepali language and respond orally to interview questions, and have a participating family member who could read and write. Unconscious or medically unstable patients and individuals with confirmed primary psychiatric illness were excluded.

Literacy was defined pragmatically for this project. Participants were first asked if they were able to write and read (yes/no), then to read a word from the 3-word registration task. They were then offered paper and pencil and invited to write anything they liked. Those answering 'no' and demonstrably unable to read or write were classified as non-literate, and presumed unable to do clock drawing.

\section{Measures}

\section{Mini-Cog versions.}

Literate participants completed the original $\mathrm{MC}$ and both versions of $\mathrm{MMC}$ in random order. Non-literate participants were not asked to do the $\mathrm{MC}$, which requires drawing a clock, but completed both versions of MMC.

\section{Measure feasibility and acceptability using questionnaires.}

Participants rated each component of the $\mathrm{MC}$ and the two MMC versions (3-word registration, 3 questions; each distractor, 3 questions) using a 6-point scale developed for this study (Appendix 2). Each question was scored 
Yes (1 point) or No (0 point). The total score was calculated by adding the score of registration component and the score of one distractor for a total score of 0-6 for each of the three test versions. Higher scores indicate better acceptability and feasibility.

\section{Preliminary validation of modified Mini-Cog versions using Dementia Severity Rating Scale:}

Validation of a new or modified screening test requires comparison with an external standard. For non-literate as well as literate individuals, we used a structured proxy interview, the Dementia Severity Rating Scale (DSRS). The DSRS, based on the Clinical Dementia Rating, taps everyday cognitive functioning based on observations of a family member or another individual who knows the person well $(11,12)$. Its psychometric properties have been well established in studies from the United States [interrater reliability $=0.9$, intrarater reliability $=0.8$, internal consistency reliability $>0.7$, validity good (11-13)]. Scores can range from $0-54$ (normal cognition to severe dementia, higher scores indicating greater impairment).

\section{Statistical analysis}

Demographic variables were analyzed using descriptive statistics. The Chi-square test was used to examine the association between the variables. Concurrent validity was evaluated comparing MMC versions with DSRS. Phi or Cramer's V, were used (as the date in min cog are analyzed in the form of categorical scale) to report strength of association for $2 \times 2$ contigency table and bigger than $2 \times 2$ tabulaiton respectively (14). Mann- Whitney $U$ test was used to evaluate group differences. The significance level was set at $p<0.05$. Data were analyzed using SPSS version 21.0.

\section{Results}

Data were collected from 63 participants, including adults with no neurological diagnosis (75\%) and those with a neurological diagnosis (25\%). Two thirds of participants were non-literate (unable to read or write at all). Demographic and clinical characteristics of participants are presented in Table 1. 
Table 1

Demographic and clinical characteristics of the participants

\begin{tabular}{|c|c|c|c|c|}
\hline \multirow[t]{2}{*}{ Variables } & \multicolumn{4}{|l|}{ Mean (SD) / N (\%) } \\
\hline & $\begin{array}{l}\text { Participants with no } \\
\text { neurological diagnosis }\end{array}$ & $\begin{array}{l}\text { Participants with } \\
\text { neurological diagnosis }\end{array}$ & $\begin{array}{l}\text { All } \\
\text { participants }\end{array}$ & $\begin{array}{l}\text { Literate } \\
\text { participants }\end{array}$ \\
\hline $\begin{array}{l}\text { Sample } \\
\text { size (n) }\end{array}$ & 45 & 18 & 63 & 21 \\
\hline $\begin{array}{l}\text { Age } \\
\text { (years) }\end{array}$ & $68.3(6.9)$ & $59.9(16.7)$ & $65.9(11.2)$ & $65.1(11.3)$ \\
\hline \multicolumn{5}{|l|}{ Gender } \\
\hline Male & $26(57.8 \%)$ & $8(44.4 \%)$ & 34 (54.0 \%) & 16 (76.2 \%) \\
\hline Female & $19(42.2 \%)$ & $10(55.6 \%)$ & $29(46.0 \%)$ & $5(23.8 \%)$ \\
\hline \multicolumn{5}{|l|}{ Literacy } \\
\hline Literate & $18(40.0 \%)$ & $3(16.7 \%)$ & $21(33.3 \%)$ & $21(100 \%)$ \\
\hline $\begin{array}{l}\text { Non- } \\
\text { literate }\end{array}$ & $27(60.0 \%)$ & $15(83.7 \%)$ & $42(66.7 \%)$ & - \\
\hline $\begin{array}{l}\text { DSRS } \\
\text { score }\end{array}$ & $6.5(9.4)$ & $11.0(8.8)$ & $7.8(9.4)$ & $6.8(9.9)$ \\
\hline $\begin{array}{l}\text { MMC with } \\
\text { SST }\end{array}$ & $3.5(1.4)$ & $3.0(1.5)$ & $3.4(1.5)$ & - \\
\hline $\begin{array}{l}\text { MMC with } \\
\text { MPT }\end{array}$ & $3.4(1.4)$ & $3.0(1.6)$ & $3.3(1.5)$ & - \\
\hline MC & - & - & - & $3.6(1.5)$ \\
\hline \multicolumn{5}{|c|}{$\begin{array}{l}\text { In the table; MC: Mini-Cog. MMC: Modified Mini-Cog. SST: Serial Subtraction Task. MPT: Multistep } \\
\text { Performance Task. DSRS: Dementia Severity Rating Scale. Neurological diagnosis: stroke }=13(20.6 \%) \text {, } \\
\text { traumatic brain injury }=4(6.3 \%) \text {, Alzheimer's disease }=1(1.6 \%) \text {. Out of } 21 \text { literate participants, with no } \\
\text { diagnosis of neurological disease: } 18(85.7 \%) \text {, and with diagnosis of neurological disease (stroke: } 2 \text {, } \\
\text { traumatic brain injury: } 1): 3(14.3 \%) \text {. There were no significant differences }(p>0.05) \text { on any variables } \\
\text { between two (with neurological and without neurological) groups. }\end{array}$} \\
\hline
\end{tabular}

In individuals without neurological disorder having word recall score of $3 / 3(n=28 ; 11$ literate, 17 non-literate), literacy was strongly associated with self-reported understanding of the CDT $\left(\chi^{2}: 20.5, p<0.001\right.$, strength of association: 0.9). There was no significant difference between literate and non-literate groups on the SST $(n=28$, Mann-Whitney U: 66.5, $p=0.13)$ or the MPT ( $(n=28$, Mann-Whitney U: $77.5, p=0.34)$.

The association between different Mini-Cog versions is shown in Table 2. The DSRS was significantly correlated with all Mini-Cog versions (Phi or Cramer's V ranged from 0.7 to $0.9, p<0.05$ ) in literate as well as non-literate participants. Both versions of MMC was significantly associated with MC (Phi or Cramer's V: $0.7, p=0.003$ ) in literate participants. Two versions of MMC were also significantly associated with each other (Phi or Cramer's V ranged from 0.6 to $1.0, p<0.05$ ) separately in different groups; literate, non-literate, with no neurological diagnosis, with neurological diagnosis and total participants. 
Table 2

Association between different Mini-Cog versions and with DSRS

\begin{tabular}{|c|c|c|c|c|c|c|c|c|c|c|}
\hline \multirow[t]{3}{*}{ Variab } & & \multicolumn{3}{|c|}{$\begin{array}{l}\text { Literate participants }(\mathrm{n}= \\
21)\end{array}$} & \multicolumn{4}{|c|}{ Non-literate participants $(n=42)$} & \multicolumn{2}{|c|}{$\begin{array}{l}\text { Total } \\
\text { participants }(n= \\
63)\end{array}$} \\
\hline & & \multirow[t]{2}{*}{$\begin{array}{l}\text { MMC } \\
\text { with } \\
\text { MPT }\end{array}$} & \multirow[t]{2}{*}{$\begin{array}{l}\text { MMC } \\
\text { with } \\
\text { SST }\end{array}$} & \multirow[t]{2}{*}{$\mathrm{MC}$} & \multicolumn{2}{|c|}{$\begin{array}{l}\text { With no } \\
\text { neurological } \\
\text { diagnosis }(n= \\
27)\end{array}$} & \multicolumn{2}{|c|}{$\begin{array}{l}\text { With } \\
\text { neurological } \\
\text { diagnosis (n } \\
=15 \text { ) }\end{array}$} & \multirow[t]{2}{*}{$\begin{array}{l}\text { MMC } \\
\text { with } \\
\text { MPT }\end{array}$} & \multirow[t]{2}{*}{$\begin{array}{l}\text { MMC } \\
\text { with } \\
\text { SST }\end{array}$} \\
\hline & & & & & $\begin{array}{l}\text { MMC } \\
\text { with } \\
\text { MPT }\end{array}$ & $\begin{array}{l}\text { MMC } \\
\text { with } \\
\text { SST }\end{array}$ & $\begin{array}{l}\text { MMC } \\
\text { with } \\
\text { MPT }\end{array}$ & $\begin{array}{l}\text { MMC } \\
\text { with } \\
\text { SST }\end{array}$ & & \\
\hline \multirow[t]{3}{*}{ MC } & $x^{2}$ & 48.4 & 42.0 & & & & & & & \\
\hline & p-value & $0.003^{\star}$ & $0.003^{*}$ & - & - & - & - & - & - & - \\
\hline & $\begin{array}{l}\text { Phi/Cramer's } \\
\text { V }\end{array}$ & 0.7 & 0.7 & & & & & & & \\
\hline \multirow{3}{*}{$\begin{array}{l}\text { MMC } \\
\text { with } \\
\text { SST }\end{array}$} & $x^{2}$ & 42.4 & & & 31.1 & & 10.3 & & 63.8 & \\
\hline & p-value & $0.002 *$ & - & - & $0.03^{*}$ & - & $0.01^{*}$ & - & $<.001 *$ & - \\
\hline & $\begin{array}{l}\text { Phi/Cramer's } \\
\text { V }\end{array}$ & 0.7 & & & 0.6 & & 0.8 & & 1.0 & \\
\hline \multirow[t]{3}{*}{ DSRS } & $\chi^{2}$ & 73.1 & 69.1 & 81.5 & 66.1 & 90.2 & 44.7 & 32.9 & 139.8 & 149.5 \\
\hline & p-value & $0.01^{*}$ & $0.003^{*}$ & $0.003 *$ & $0.04^{\star}$ & $0.007 *$ & $0.02^{*}$ & $0.04 *$ & $0.002^{*}$ & $<.001 *$ \\
\hline & $\begin{array}{l}\text { Phi/Cramer's } \\
\text { V }\end{array}$ & 0.8 & 0.9 & 0.9 & 0.8 & 0.8 & 0.8 & 0.8 & 0.7 & 0.7 \\
\hline
\end{tabular}

Scores for acceptability and feasibility of different Mini-Cog versions are shown in Fig. 2. In literate participants without neurological disease, scores for all three versions were essentially identical. When all participants (nonliterate, literate, with or without neurological diagnosis) were included in the analysis, mean and standard deviations of acceptability and feasibility scores for the two MMC versions were similar to each other and to scores for literate subjects, but much lower (and standard deviation much higher) for the original MC owing to the inability of non-literate participants to do the CDT.

\section{Discussion}

Individuals lacking basic literacy are difficult to screen for cognitive impairment. Our study is unusual in its effort to retain the brevity and simple scoring of the Mini-Cog, a brief cognitive screening tool, while replacing its literacy-sensitive clock drawing task (8) with everyday complex cognitive tasks familiar to both literate and nonliterate individuals. The two resulting alternate versions of the Mini-Cog, SST and MPT, correlated significantly 
and similarly with the DSRS, a proxy-rated cognitive impairment screening tool. Both non-literate and literate individuals rated both the SST and MPT applicable, acceptable and feasible.

The absence of significant group differences between literate and non-literate individuals in SST or MPT score, and their significant association with the DSRS as rated by family informants, provides preliminary evidence that both modified versions of the Mini-Cog may be acceptable screening tests applicable to both literate and nonliterate individuals. While the SST and MPT lack the visual performance record of the original Mini-Cog, the scoring was set to replicate the binary method established for the CDT in the original Mini-Cog (1). Instructions for administering both modified versions are simple; reducing the chance of spurious poor performance due to inadequate test administration is low. Furthermore, because there are two distractors, either one can be selected based on participants' choice and ability. If an individual fails one, a second distractor can be tried. This is in line with the administration strategies of MMSE (9). However, equivalent performance of the two versions cannot be inferred from this proof-of-concept study.

The validity of the two MMC versions as screens for cognitive impairment was evaluated by comparing results with the informant-rated DSRS; correlations were large (15) in non-literate groups with and without neurological disease. The SST and MPT were strongly correlated with each other, the CDT, and the DSRS in literate participants who could perform all three MC versions. Results demonstrated high acceptability and feasibility for both CDT substitutes in the sample as a whole.

\section{Limitations}

As a proof-of-concept study, our sample size is relatively small and no independent, fully objective assessment of cognition was possible. However, the association of scores with the DSRS - an acceptable method for classifying cognitive function based on informant observations - is a reasonable place to start (11) in settings and populations very different from those for which cognitive tests are typically created, including developing countries where the illiteracy rate of the older population is high (15). Although our initial findings are promising, they cannot establish the true equivalence of the MMC versions. There might be a selection bias when we recruited only those participants whose family members were literate. However, the situation having every family member as non-literate is a rare condition.

\section{Conclusion}

Two alternate distractor tasks may successfully replace clock drawing in the Mini-Cog and improve its validity in non-literate populations, and facilitate meaningful population comparisons. The two MMC versions are promising and deserve further study as screening tools for cognitive impairment in larger, more fully characterized samples of mixed literacy, language, cultural, and clinical status.

\section{Abbreviations}

MC: Mini-Cog

MMC: Modified Mini-Cog

CDT: Clock-Drawing Test 
MMSE: Mini Mental State Examination

SST: Serial Subtraction Task

MPT: Multistep Performance Task

DSRS: Dementia Severity Rating Scale

\section{Declarations}

\section{Data Archiving}

The datasets generated and/or analyzed during the current study are available from the corresponding author on reasonable request.

\section{Statement of Ethics}

An ethical approval was taken from Kathmandu University School of Medical Sciences (KUSMS IRC: 122/18). A written informed consent was taken from all participants prior to the recruitment.

\section{Conflict of interest}

The authors declare no conflict of interest

\section{Acknowledgement}

We would like to thank the Department of Physiotherapy of Dhulikhel Hospital for providing us platform to conduct this study. We would like to express our sincere gratitude to all the participants without whom this study could not be possible. Our sincere thank goes to Dr. Soo Borson, the original tool developer who has provided us an approval to modify the tool.

\section{Funding}

There was no funding for conduction and publication of this research

\section{Availability of data and materials}

The dataset supporting the conclusion of this article is available from corresponding author on request.

\section{Authors' contributions}


SPA was responsible for literature reviews, formulating research questions and objectives, designing the study, extracting and analyzing data, interpreting results, creating tables, figures and writing the manuscript.

$\mathrm{RD}$ was responsible for helping to analyze data and interpret results, reviewing manuscripts and providing critical comments

SB was responsible to interpret results, reviewing manuscripts and providing critical comments

\section{References}

1. Borson S, Scanlan J, Brush M, Vitaliano P, Dokmak A. The mini-cog: a cognitive 'vital signs' measure for dementia screening in multi-lingual elderly. Int J Geriatr Psychiatry. 2000;15(11):1021-7.

2. Milian M, Leiherr AM, Straten G, Muller S, Leyhe T, Eschweiler GW. The Mini-Cog versus the Mini-Mental State Examination and the Clock Drawing Test in daily clinical practice: screening value in a German Memory Clinic. Int Psychogeriatr. 2012;24(5):766-74.

3. Tsoi KK, Chan JY, Hirai HW, Wong SY, Kwok TC. Cognitive Tests to Detect Dementia: A Systematic Review and Meta-analysis. JAMA Intern Med. 2015;175(9):1450-8.

4. Scanlan J, Borson S. The Mini-Cog: receiver operating characteristics with expert and naive raters. Int J Geriatr Psychiatry. 2001;16(2):216-22.

5. McCarten JR, Anderson P, Kuskowski MA, McPherson SE, Borson S. Screening for cognitive impairment in an elderly veteran population: acceptability and results using different versions of the Mini-Cog. J Am Geriatr Soc. 2011;59(2):309-13.

6. Borson S, Scanlan JM, Watanabe J, Tu SP, Lessig M. Simplifying detection of cognitive impairment: comparison of the Mini-Cog and Mini-Mental State Examination in a multiethnic sample. J Am Geriatr Soc. 2005;53(5):871-4.

7. Borson S, Scanlan JM, Chen P, Ganguli M. The Mini-Cog as a screen for dementia: validation in a populationbased sample. J Am Geriatr Soc. 2003;51(10):1451-4.

8. Lessig MC, Scanlan JM, Nazemi H, Borson S. Time that tells: critical clock-drawing errors for dementia screening. Int Psychogeriatr. 2008;20(3):459-70.

9. Folstein Marshal F SEFSE, McHugh Paul R. Mini Mental State: A Practical Method for grading Cognitive state of patients for the clinician. Journal of Psyhciatric research. 1975;12:189 - 98.

10. Kabir ZN, Herlitz A. The Bangla adaptation of Mini-Mental State Examination (BAMSE): an instrument to assess cognitive function in illiterate and literate individuals. Int J Geriatr Psychiatry. 2000;15(5):441-50.

11. Clark CM, Ewbank DC. Performance of the dementia severity rating scale: a caregiver questionnaire for rating severity in Alzheimer disease. Alzheimer Dis Assoc Disord. 1996;10(1):31-9.

12. Rikkert MG, Tona KD, Janssen L, Burns A, Lobo A, Robert P, et al. Validity, reliability, and feasibility of clinical staging scales in dementia: a systematic review. Am J Alzheimers Dis Other Demen. 2011;26(5):357-65.

13. Mitchell JC, Dick MB, Wood AE, Tapp AM, Ziegler R. The utility of the Dementia Severity Rating Scale in differentiating mild cognitive impairment and Alzheimer disease from controls. Alzheimer Dis Assoc Disord. 2015;29(3):222-8.

14. Akoglu H. User's guide to correlation coefficients. Turk J Emerg Med. 2018;18(3):91-3. 
15. Bank TW. Literacy rate, adult total (\% of people ages 15 and above) 2019 [Available from: https://data.worldbank.org/indicator/se.adt.litr.zs.

\section{Figures}

Goal: To modify Mini-Cog for inclusion of non-literate individuals in brief cognitive screening

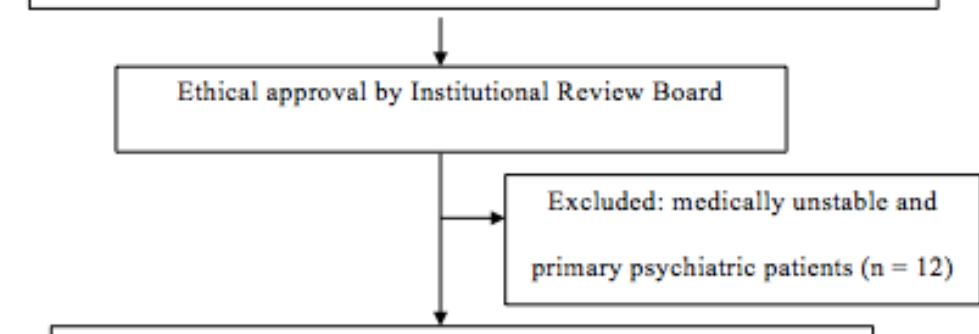

Enrolled: older adults and individuals with stroke, Parkinson's disease, traumatic brain injury or Alzheimer's disease and their family members without a neurological diagnosis $(n=63)$

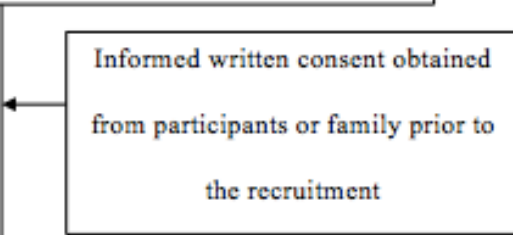

Tools for evaluating clock-drawing test substitutes for modified Mini-Cog versions:

- Mini-Cog, modified Mini-Cog (two versions), and Dementia Severity Rating Scale

- Acceptability and feasibility questionnaires

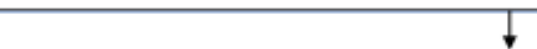

Data analysis $(n=63)$

\section{Figure 1}

Flow chart

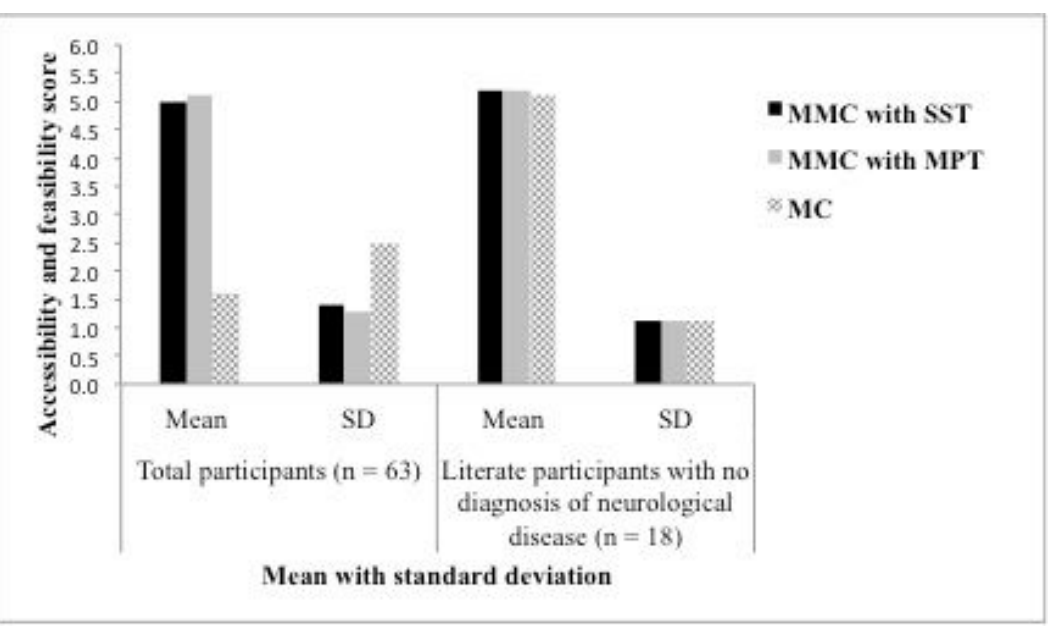




\section{Figure 2}

Accessibility and feasibility of different Mini-Cog versions. In the figure, MC: Mini-Cog, MMC: Modified Mini-Cog, SST: Serial Subtraction Task, MPT: Multistep Performance Task, SD: Standard Deviation, n: sample size

\section{Supplementary Files}

This is a list of supplementary files associated with this preprint. Click to download.

- Appendix.docx 